\title{
Deposition of Nanocrystalline Zinc-Nickel Alloys by D.C. Plating in Additive Free Chloride Bath
}

\author{
Rashid Rizwan ${ }^{1}$, Mazhar Mehmood ${ }^{1, *}$, Muhammad Imran $^{1}$, Jamil Ahmad ${ }^{1}$, \\ Muhammad Aslam ${ }^{1}$ and Javed I. Akhter ${ }^{2}$ \\ ${ }^{1}$ National Centre for Nanotechnology \& Department of Chemical and Materials Engineering, \\ Pakistan Institute of Engineering and Applied Sciences, Islamabad 45650, Pakistan \\ 2 PINSTECH, Islamabad, Pakistan
}

\begin{abstract}
Nanocrystalline zinc-nickel alloy coatings were electro-deposited in chloride bath containing $\mathrm{ZnCl}_{2}\left(50-200 \mathrm{gL}^{-1}\right), \mathrm{NiCl}_{2} \cdot 6 \mathrm{H}_{2} \mathrm{O}(50-$ $\left.200 \mathrm{gL}^{-1}\right)$ and $\mathrm{H}_{3} \mathrm{BO}_{3}\left(40 \mathrm{gL}^{-1}\right)$ at $45^{\circ} \mathrm{C}$. The initial alloy composition, as investigated by voltammetry, chronopotentiometry or EDX analysis, exhibited a pronounced dependence on the composition of plating bath. However, the alloy composition tended to approach an upper limit of 18 atomic percent when deposits grew thicker, for most of the plating bath compositions. The process was clearly the anomalous codeposition, which was considered to be due to the formation of an adsorbed layer of $\mathrm{Zn}(\mathrm{OH})_{2}$ containing nickel cations, as an intermediate product, whose composition determines the composition of the electro-deposited alloy. The electro-deposited coatings comprised of single-phase structure of $\gamma$-phase $\left(\mathrm{Ni}_{5} \mathrm{Zn}_{21}\right)$ for about $12-18$ atomic percent nickel and a mixture of $\gamma$ - and $\eta$-phases (hcp) for nickel atom percent below 8 . The grain size decreased from about $50 \mathrm{~nm}$ to $20 \mathrm{~nm}$ with decrease in nickel content away from the stoichiometric composition of $\mathrm{Ni}_{5} \mathrm{Zn}_{21}$ along with a decrease in hardness from about $450 \mathrm{KHN}$ to $150 \mathrm{KHN}$. The decrease in hardness with a decrease in grain size seems attributable to the grain boundary sliding as predominant deformation mechanism. Anodic dissolution of the alloys involved pronounced dezincification, forming $\alpha$-phase (fcc) that dissolved at the end. [doi:10.2320/matertrans.MER2007022]
\end{abstract}

(Received February 5, 2007; Accepted April 12, 2007; Published May 25, 2007)

Keywords: electrodeposition, coating, zinc-nickel alloy, chloride bath, voltammetry, chronopotentiometry, anomalous codeposition

\section{Introduction}

Electrodeposition is a versatile materials processing technique finding applications ranging from miniature electronic devices to giant industrial structures as functional and/ or aesthetic coatings. Both aqueous ${ }^{1)}$ and non aqueous ${ }^{2,3)}$ solutions have been employed for the purpose. However, the aqueous solutions have the special advantage of room temperature operation and are, therefore, preferred for large scale applications.

Zinc has been the most widely used sacrificial coating for the protection of steel from corrosion. The addition of small quantity of iron group metals such as nickel (10-18\%) to zinc deposits has been known to increase its corrosion resistance along with an improvement in mechanical properties. ${ }^{4)}$ In salt spray tests, the ability of electro-deposited $\mathrm{Zn}-\mathrm{Ni}$ alloy coatings to protect steel from corrosion is found to be 3-4 times better than pure zinc coating, although the cost is only 2 times higher. On the other hand, the hardness of electrodeposited zinc alloys containing 10-20\% nickel is 3-6 times higher than that of pure zinc deposit. ${ }^{5)}$ Ductility of these alloys is also better than zinc. ${ }^{4)}$ Improved corrosion resistance and hardness (wear resistance) also allow using relatively thinner deposits required for better formability and weldability. ${ }^{6}$ The alloy coatings also allow spot welding because of higher melting temperature of the intermetallic phases. $^{4)}$

Mostly, the electrolytic codeposition of $\mathrm{Zn}-\mathrm{Ni}$ alloys is anomalous in nature which means the deposition of a relatively noble metal, i.e., nickel, is hindered before the deposition of other alloy constituent, i.e., zinc, also starts taking place. ${ }^{7)}$ Different alkaline and acid type plating baths are in use. ${ }^{4)}$ The acid type baths are further subdivided into

*Corresponding author, E-mail: mazhar@pieas.edu.pk chloride type and sulfate type baths. The sulfate type baths are used for high-speed alloy plating with simple shapes whereas chloride baths are preferred for higher throwing power to plate intricate shapes. ${ }^{8}$ The higher micro-throwing power of chloride bath also ensures an improved corrosion resistance. ${ }^{4)}$

Apart from electroplating, a number of authors have performed electrochemical studies on $\mathrm{Zn}-\mathrm{Ni}$ system, involving voltammetry or chronoptentiometry. However, any systematic study to explain the anodic peaks (waves) in the voltammograms and anodic plateaus in the chronopotentiograms remained absent after the work of Swathirajan, ${ }^{9)}$ who was mostly followed to describe the dissolution as occurring in three main stages, namely dezincification/dissolution of $\eta$ (Zn(Ni), hcp) plus $\gamma$ - $\left(\mathrm{Ni}_{5} \mathrm{Zn}_{21}\right.$, bcc) phases, $\alpha$-phase $(\mathrm{Ni}(\mathrm{Zn})$, fcc), and (pure) porous nickel (fcc) with increasing order of dissolution potentials. The dissolution potential of the presumed porous nickel, as formed by prior dezincification, was significantly lower than that of the electrodeposited nickel. Recently, Petrauskas et al. ${ }^{10,11)}$ identified dissolution of $\beta(\mathrm{NiZn})$ at the potentials previously assigned to the dissolution of porous nickel. Therefore, it is required that more investigations are performed to clarify the dissolution behavior of $\mathrm{Ni}-\mathrm{Zn}$ alloys in different electrolytes.

Among chloride baths for deposition of $\mathrm{Zn}-\mathrm{Ni}$ alloys, addition of ammonium chloride or acetate has been common. Other additives are also added for improving the leveling. On the other hand, Erb et al. ${ }^{12,13)}$ has employed boric acid without addition of ammonia or acetate. They were able to prepare good deposits by pulse plating. They were also able to control the grain size to nano-scale range. It is worthmentioning that nanocrystalline alloys exhibit extremely high corrosion resistance comparable to extremely homogeneous amorphous counterparts, ${ }^{14-19)}$ and extra-ordinary high strength with reasonable ductility depending on the grain 
Table 1 Composition of plating baths employed for the study.

\begin{tabular}{rrrrl}
\hline No & $\begin{array}{c}\text { Conc. of } \mathrm{ZnCl}_{2} \\
\left(\mathrm{gL}^{-1}\right)\end{array}$ & $\begin{array}{c}\text { Conc. of } \\
\mathrm{NiCl}_{2} .6 \mathrm{H}_{2} \mathrm{O} \\
\left(\mathrm{gL}^{-1}\right)\end{array}$ & $\begin{array}{c}\text { Boric acid } \\
\left(\mathrm{gL}^{-1}\right)\end{array}$ & $\begin{array}{c}\text { Referred in the } \\
\text { text as }\end{array}$ \\
\hline 1 & 200 & 0 & 40 & Bath 1 $(200 / 0)$ \\
2 & 0 & 200 & 40 & Bath 2 $(0 / 200)$ \\
3 & 200 & 200 & 40 & Bath 3 $(200 / 200)$ \\
4 & 200 & 50 & 40 & Bath 4 $(200 / 50)$ \\
5 & 50 & 200 & 40 & Bath 5 $(50 / 200)$ \\
6 & 50 & 50 & 40 & Bath 6 $(50 / 50)$ \\
7 & 100 & 100 & 40 & Bath 7 $(100 / 100)$ \\
8 & 150 & 150 & 40 & Bath 8 $(150 / 150)$ \\
9 & 200 & 100 & 40 & Bath 9 $(200 / 100)$ \\
10 & 100 & 200 & 40 & Bath 10 $(100 / 200)$ \\
\hline
\end{tabular}

size and deformation mechanism..$^{20,21)}$ Electrochemical study and DC plating in the bath based on zinc and nickel chlorides and boric acid without any addition has not yet been focused upon to the best of our knowledge.

The purpose of the present study is to explore the electrodeposition of nanocrystalline $\mathrm{Zn}-\mathrm{Ni}$ alloys by DC plating in the additive free chloride baths. Particular emphasis has been laid on effect of concentrations of electroactive species (salts) on the composition, texture and quality of the deposit in addition to anodic dissolution behavior.

\section{Experimental}

Electrochemical measurements and electrodeposition were performed using Potentiostat/Galvanostat AMEL Model2051 and Function Generator AMEL Model-568. Different compositions of plating bath were employed as shown in Table 1. For referring to the bath compositions, concentration of $\mathrm{ZnCl}_{2}$ and $\mathrm{NiCl}_{2} \cdot 6 \mathrm{H}_{2} \mathrm{O}$ will be written in the parenthesis as numerator and denominator, respectively, wherever found necessary. The analytical grade chemicals were used along with doubly distilled water to prepare the solutions. The $\mathrm{pH}$ was measured by a $\mathrm{pH}$ meter, (Model $\mathrm{PH}$ 330/SET - 0, 82362 WTW, Germany). For all measurements, the initial $\mathrm{pH}$ of the bath was $3.6 \pm 0.1$ and it remained almost same during whole experiment. All the experiments were performed in a $100 \mathrm{ml}$ beaker with an electrolyte volume of about $80 \mathrm{ml}$. No agitation was used and the temperature was maintained at $45 \pm 0.5^{\circ} \mathrm{C}$ by placing the cell in a hot water bath.

For electrochemical studies (cyclic voltammetry \& reverse chronopotentiometry), a platinum strip (with an exposed area of $1 \mathrm{~cm}^{2}$ ) was used as a working electrode. It was cleaned with conc. $\mathrm{H}_{2} \mathrm{SO}_{4}$, and degreased with acetone using ultrasonic vibrator followed by rinsing in distilled water. Another platinum strip and a saturated calomel electrode (SCE) were used as counter and reference electrodes, respectively. The scan rate for cyclic voltammetry was $0.05 \mathrm{Vs}^{-1}$. All the potentials in this paper are presented with respect to the SCE.

For electrodeposition of alloy coatings, commercial purity cold rolled copper sheet with an exposed area of $2 \mathrm{~cm}^{2}$ was used as a substrate. The copper substrate was mechanically polished using emery papers up to fine grit of 1200 , followed

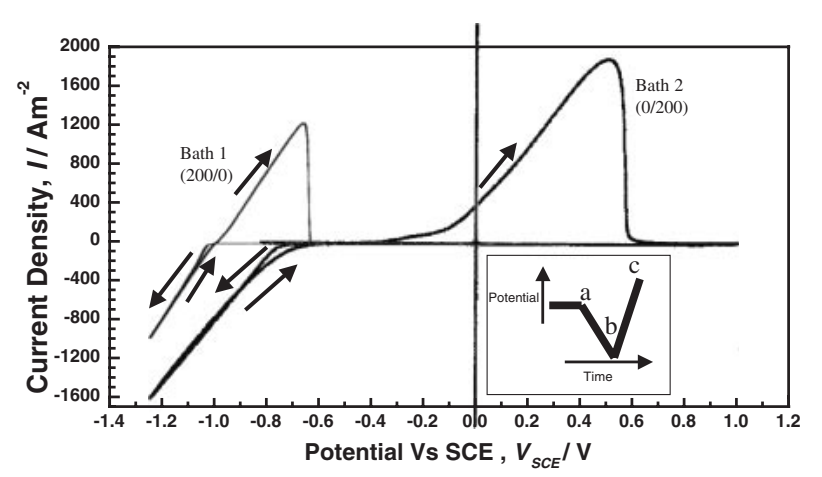

Fig. 1 Typical cyclic voltammograms obtained on platinum electrode in baths 1 and 2 at $45^{\circ} \mathrm{C}$. The scan rate was $0.05 \mathrm{Vs}^{-1}$ and the reversal potential was $-1.25 \mathrm{~V}$ (In the parenthesis, concentrations $\left(\mathrm{gL}^{-1}\right)$ of $\mathrm{ZnCl}_{2}$ and $\mathrm{NiCl}_{2} \cdot 6 \mathrm{H}_{2} \mathrm{O}$ have been presented in the form of numerator and denominator, respectively).

by ultrasonic cleaning in acetone. Before deposition, the copper substrate was chemically etched in $10 \%$ sulfuric acid for about 5-6 seconds followed by rinsing with distilled water. Perfect adhesion of the deposits with the substrate was thus ensured. Chemical composition of the electrodeposits was determined using Energy Dispersive X-ray Spectroscopy (EDS) system attached with Scanning Electron Microscope (SEM), LEO 440. The analysis was performed at 2 or 3 locations on the surface of the sample. The variation of composition on a given sample was found to be less than $1 \%$. Average values, thus obtained, have been reported in the results. The compositions of the alloys presented in the following sections are given in atomic percent. X-ray diffractometer (XRD, Rigaku Model DMAX III) with $\mathrm{Cu} \mathrm{K} \mathrm{K}_{\alpha}$ radiation was used to obtain XRD patterns using standard $\theta$ $2 \theta$ geometry. X-Ray peak broadening was used to estimate the grain size with the help of Scherrer's formula. ${ }^{22)}$

\section{Results}

\subsection{Electrochemical study \\ 3.1.1 Voltammetry}

Figure 1 shows typical cyclic voltammograms obtained on platinum in bath 1 and bath 2, (as referred in Table 1). The inset in Fig. 1 shows a schematic diagram of potential versus time sweep employed for obtaining the voltammograms. The potential was cathodically scanned from $0 \mathrm{~V}$ (point a) to a prescribed value (point b) followed by reversal of the potential sweep for complete anodic dissolution of cathodically deposited metal or alloy.

During cathodic scan in bath 1 , containing $200 \mathrm{gL}^{-1}$ zinc chloride, deposition of zinc starts at a potential around $-1.03 \mathrm{~V}$. During the anodic scan, the current suddenly drops to about zero after following a maximum that is typical for the anodic dissolution of solid films. ${ }^{23)}$ Deposition of nickel in bath 2 , containing $200 \mathrm{gL}^{-1}$ nickel chloride (hexahydrated), begins at a potential of about $-0.78 \mathrm{~V}$, and dissolution commences at a potential of about $-0.37 \mathrm{~V}$. The more positive deposition and dissolution potential for nickel in comparison with zinc is due to the fact that nickel is relatively noble for redox reaction with respect to zinc. ${ }^{24)}$ The potential at which nickel starts depositing and its dissolution com- 

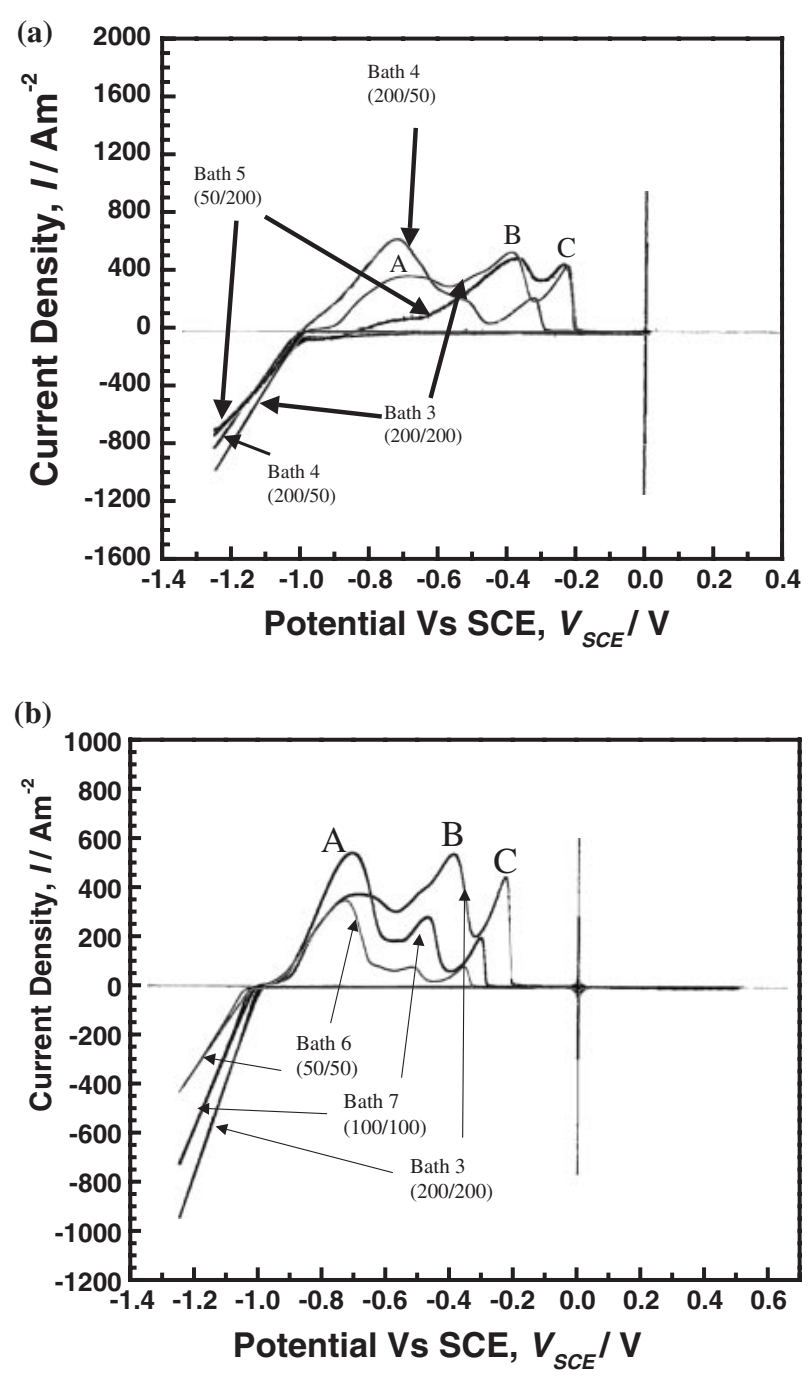

Fig. 2 Typical cyclic voltammograms obtained on platinum electrode in selected baths at $45^{\circ} \mathrm{C}$. The relative amounts (in $\mathrm{gL}^{-1}$ ) of the solution constituents are different in (a) and equal in (b). The scan rate was $0.05 \mathrm{Vs}^{-1}$ and the reversal potential was $-1.25 \mathrm{~V}$.

mences are significantly different from each other, which indicates a resistance in dissolution possibly due to passivation of electro-deposited nickel.

Figure 2(a) and (b) show typical cyclic voltammograms obtained on platinum electrode in different baths covering a wide range of zinc and nickel chloride concentrations. Only one cathodic wave is observed. The cathodic current density increases with an increase in the concentration of both the electro-active species (zinc \& nickel) in the bath. Therefore, cathodic response should be related with their electroreduction. However, the alloy deposition takes place at potentials where deposition of zinc is also allowed. Before this, the cathodic current is almost zero, indicating a strong hindrance in the deposition of nickel. This is a typical example of anomalous codeposition. Since the chemical potentials of individual alloying elements depend on the alloy composition, ${ }^{25)}$ the dissolution potential of the alloy constituents may also depend on the alloy composition. Accordingly, the multiple numbers of anodic peaks in Fig. 2 should be associated with the dissolution of nickel and zinc from various intermetallic phases or solid solutions. The relative

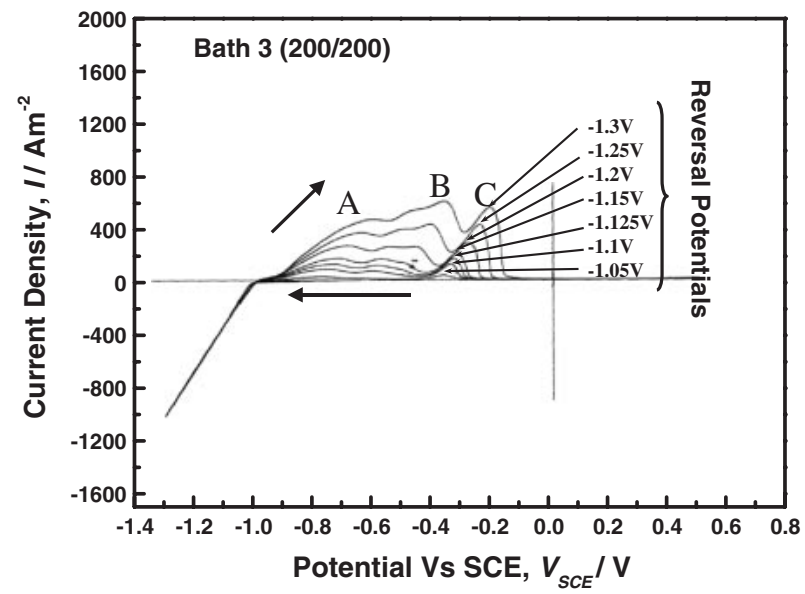

Fig. 3 Typical cyclic voltammograms obtained on platinum electrode in bath 3 at $45^{\circ} \mathrm{C}$ as a function of reversal potential. The scan rate was $0.05 \mathrm{Vs}^{-1}$.

proportion of the charge associated with three main anodic waves, i.e., $\mathrm{A}, \mathrm{B}$, and $\mathrm{C}$ depend on the concentration of bath constituents. This suggests that the composition of the electrodeposited alloy depends on bath composition. As shown in Fig. 3, the nature and the relative proportion of the anodic waves $\mathrm{A}, \mathrm{B}$, and $\mathrm{C}$ typically remain unchanged by shift of reversal potential. Therefore, the nature (and the chemical composition) of the deposit seems to remain same in spite of extending the deposition potential in the negative direction, suggesting no appreciable effect of the deposition potential on the alloy composition. This behavior may also be related with anomalous codeposition.

\subsubsection{Chronopotentiometry}

Figure 4(a) shows typical reverse chronopotentiograms obtained on platinum in different solutions. Three anodic plateaus related with alloy dissolution are observed, namely I, II, and III, which seem to correspond to the main anodic peaks of the voltammograms, i.e., A, B, and C, respectively. The plateau $\mathrm{I}$ in case of bath 4 appears at the same potential where pure zinc is dissolved in bath 1 . Hence, it corresponds to the dissolution of $\eta$-phase (which is $\eta$ - Zn (hcp) containing dissolved nickel). The same plateau appears at slightly higher potentials in the other baths containing higher concentration of nickel chloride, indicating a gradual rise in the nickel content of the $\eta$-phase with an increase in nickel concentration in the bath. This is in agreement with a similar shift of peak $\mathrm{A}$ in the voltammograms (Fig. 2). Furthermore, the relative amount of $\eta$-phase decreases with increase in nickel concentration of the plating bath as indicated by the decrease in charge associated with plateau I in chronopotentiograms. These observations are in agreement with voltammetry.

Figure 4(b) shows a typical reverse chronopotentiogram obtained in bath 9 . The deposition time was $1.8 \mathrm{ks}$. The plateau $\mathrm{I}$ is almost absent, which suggests that the $\eta$ phase does not form after electrodeposition for $1.8 \mathrm{ks}$ in this bath, in contrast to the deposition for $180 \mathrm{~s}$. In order to determine the phases that dissolve at the plateau II and III, various samples were prepared by deposition for $1.8 \mathrm{ks}$ in the same solution followed by dissolution for various time intervals, as corresponding to 1-5 positions indicated on the chronopotentiogram (Fig. 4(b)). The XRD patterns exhibited by these 

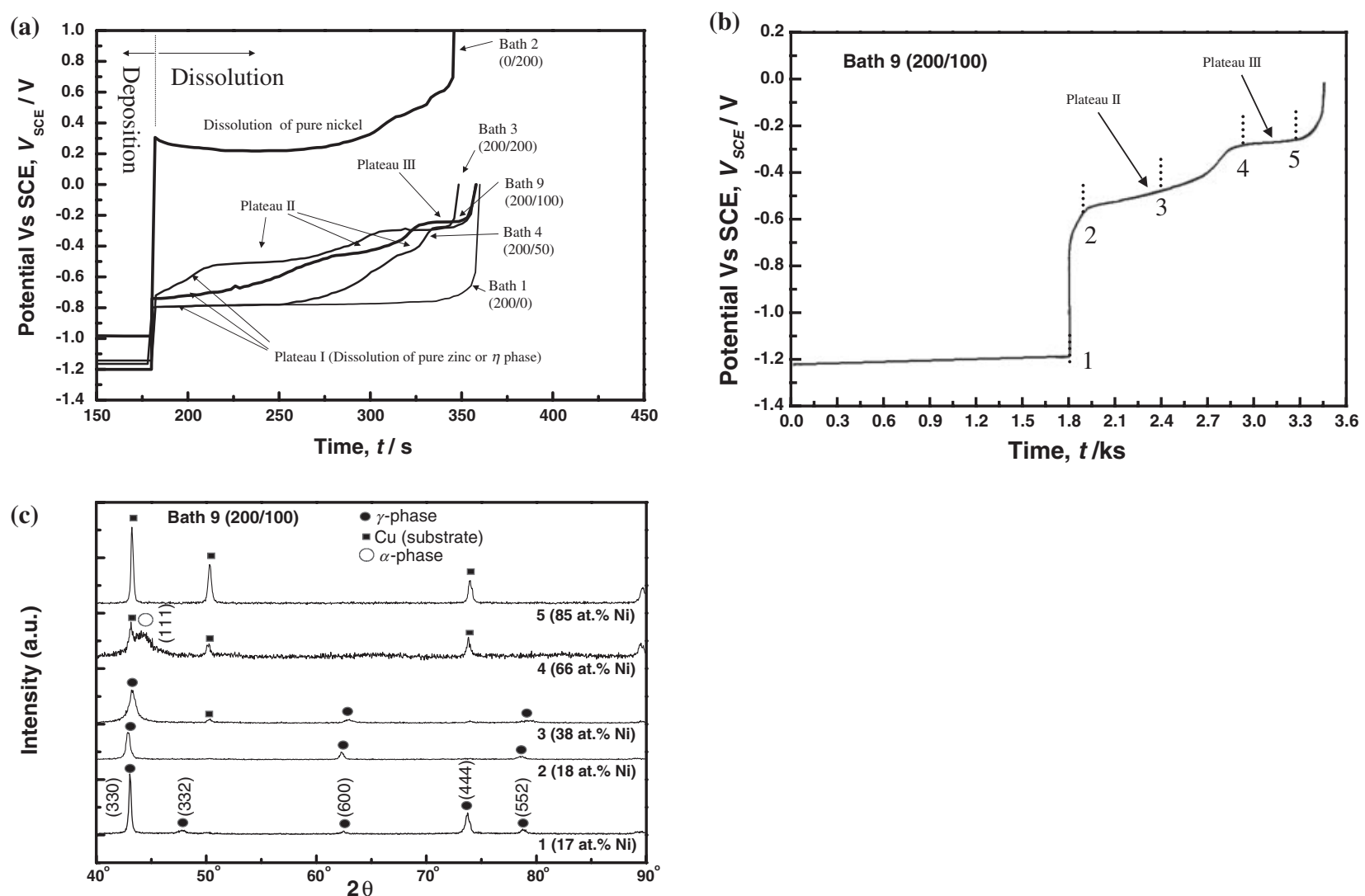

Fig. 4 Typical reverse chronopotentiogram(s) obtained on platinum in (a) selected baths 1, 2, 3, 4 and 9 with deposition time of $180 \mathrm{~s}$ at $500 \mathrm{Am}^{-2}$ and (b) bath 9 with deposition time of $1.8 \mathrm{ks}$ at $700 \mathrm{Am}^{-2}$, followed by dissolution at the same current densities, along with (c) XRD patterns and alloy compositions of samples prepared as in (b) with partial dissolution of the deposits for $0 \mathrm{~s}(1)$, 105 s (2), 600 s (3), $1.14 \mathrm{ks}(4), 1.44 \mathrm{ks}(5)$, corresponding to the various positions as marked in (b).

samples along with their compositions are shown in Fig. 4(c). The $\eta$-phase is not observed after electrodeposition for $1.8 \mathrm{ks}$, in agreement with the chronopotentiogram (Fig. 4(b)). It may be noticed that $\gamma$-phase (an intermetallic phase also known as $\mathrm{Ni}_{5} \mathrm{Zn}_{21}$ ) is present at plateau II, although the nickel content of the deposit reaches above $40 \%$ as examined by EDX analysis. The dezincification of $\gamma$-phase is also confirmed from shift of X-ray reflections towards higher angles as shown in Fig 4(c). The alloy composition at plateau III lies above $60 \% \mathrm{Ni}$. The corresponding XRD pattern indicates the formation of $\alpha$-phase (i.e., $\alpha$-Ni (fcc) with large concentration of zinc in the solid solution). Hence the dezincification of $\gamma$-phase at plateau II leads to the formation of $\alpha$ phase. In turn, the $\alpha$ phase undergoes further dezincification at plateau III. Considering this dissolution behavior, the main anodic peaks $\mathrm{B}$ and $\mathrm{C}$ in the voltammograms (Fig. 2) can also be assigned to the dezincification and dissolution of $\gamma$ and $\alpha$ phases, respectively.

\subsection{Electroplating}

The alloy composition after electroplating at $700 \mathrm{Am}^{-2}$ in different solutions is shown in Fig. 5. The nickel content of the alloys tends to increase with the time of deposition. It is also influenced by bath composition particularly for shorttime deposition, in agreement with voltammetry and chronopotentiometry. Nevertheless, the maximum nickel content in the alloy is about $18 \%$ as observed in a number of baths for

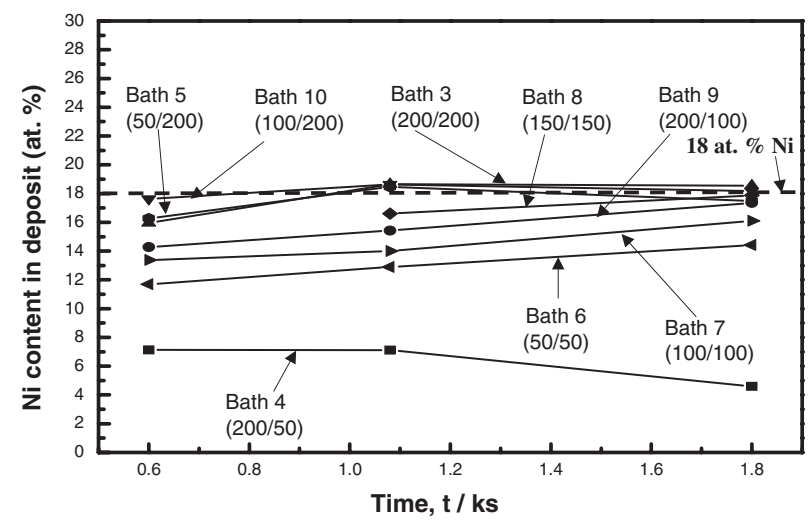

Fig. 5 Compositions of the alloys electro-deposited on copper substrate from different baths at a current density of $700 \mathrm{Am}^{-2}$, as a function of deposition time.

deposition times of 1.08 and $1.8 \mathrm{ks}$. Consequently, about $18 \%$ nickel seems to be an upper limit in the additive free chloride baths employed in this work.

Figure 6 shows typical XRD patterns of the alloy deposits obtained on copper from various baths by DC plating at $700 \mathrm{Am}^{-2}$. As exhibited by the voltammograms and chronopotentiograms (Figs. 2-4), the $\eta$-phase is formed in all the solutions invariably with or without $\gamma$-phase when a thin alloy deposit is obtained (section 3.1). By contrast, the XRD patterns of relatively thicker deposits formed by DC plating, 
(a)
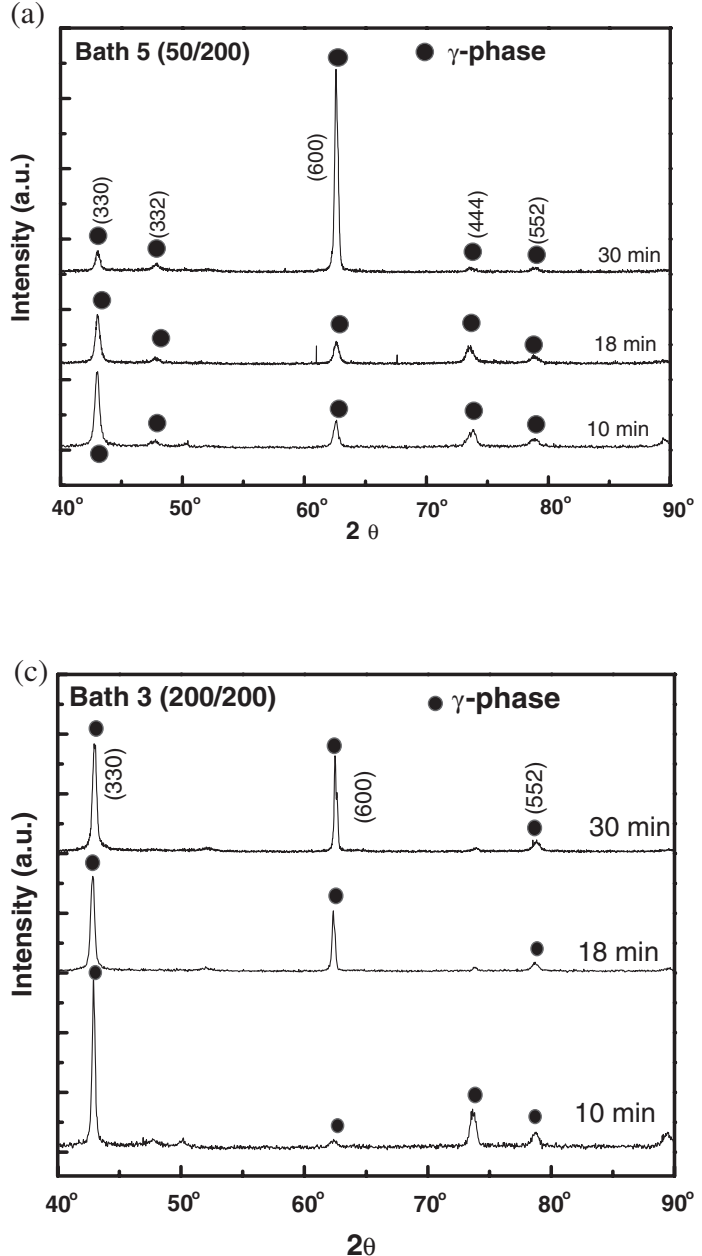

(e)

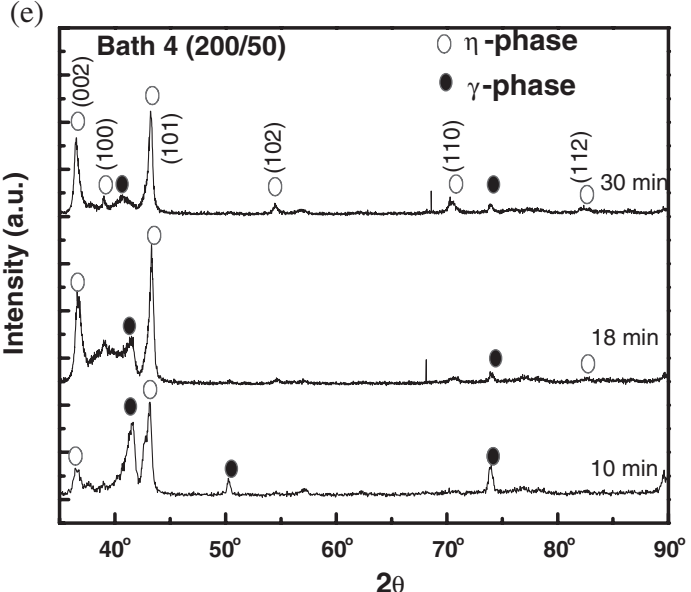

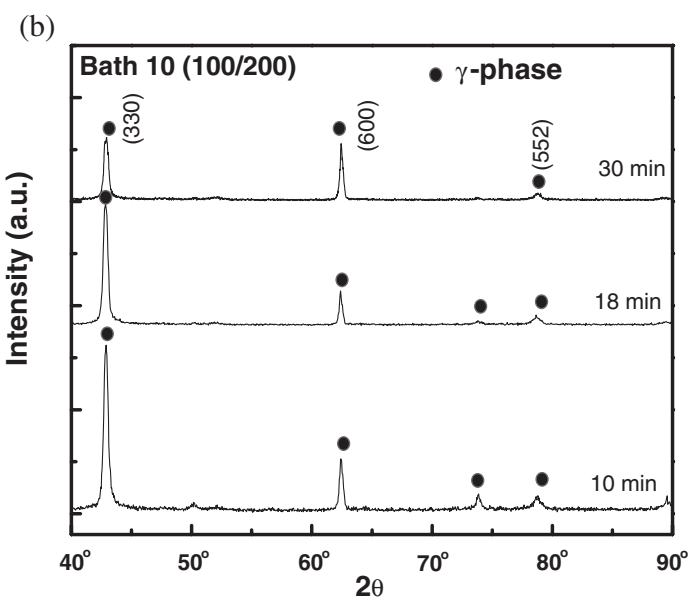

(d)

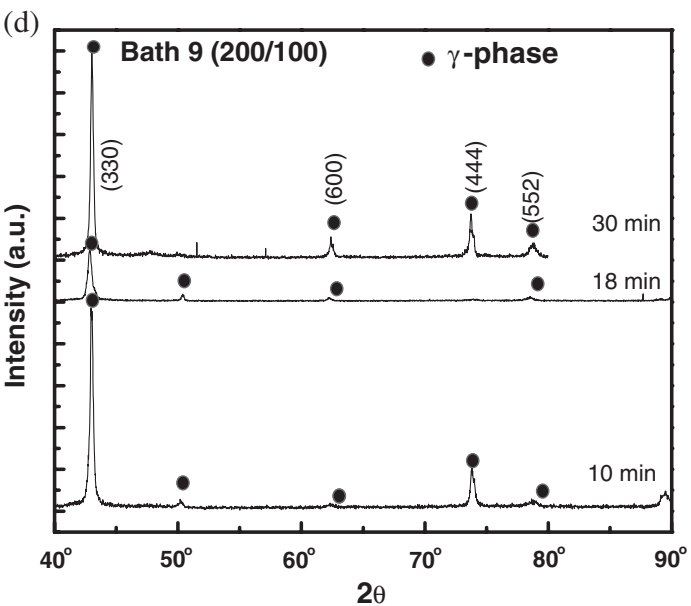

Fig. 6 Typical XRD patterns (using $\mathrm{Cu} \mathrm{K}_{\alpha}$ radiation) of the alloys electro-deposited at a current density of $700 \mathrm{Am}^{-2}$ in (a) bath 5 , (b) bath 10 , (c) bath 3 , (d) bath 9 and (e) bath 4 at $45^{\circ} \mathrm{C}$.

shown in Fig. 6 (a-d) typically exhibit the formation of only $\gamma$ phase in a variety of baths. This may suggest that $\eta$-phase is formed in these baths only at initial stages and then it dies out due to preferential growth of $\gamma$-phase, due to increase in nickel content of alloy with deposition time. In bath 4 , which contains $\mathrm{ZnCl}_{2}\left(200 \mathrm{gL}^{-1}\right)$ and $\mathrm{NiCl}_{2} \cdot 6 \mathrm{H}_{2} \mathrm{O}\left(50 \mathrm{gL}^{-1}\right)$, both $\eta$ and $\gamma$-phases are obtained in thick deposits as shown in Fig. 6(e). This may be related with the fact that nickel content of the electrodeposits decreases with deposition time (Fig. 5), in contrast to general behavior of other baths. The nickel rich $\alpha$-phase is not found in the electrodeposits. Hence, it is confirmed that $\alpha$-phase forms only by anodic dezincification of $\gamma$-phase during cyclic voltammetry and reverse chronopotentiometry. It may be noticed that the relative intensities of (330) and (600) reflections of $\gamma$-phase vary, suggesting a change in the preferred texture from one 
(a)

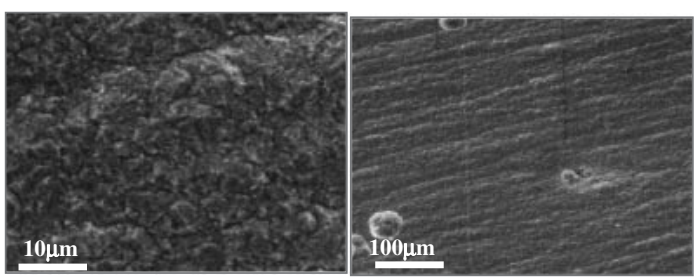

(b)

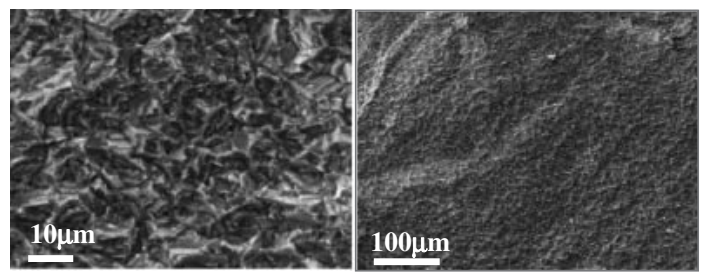

(c)

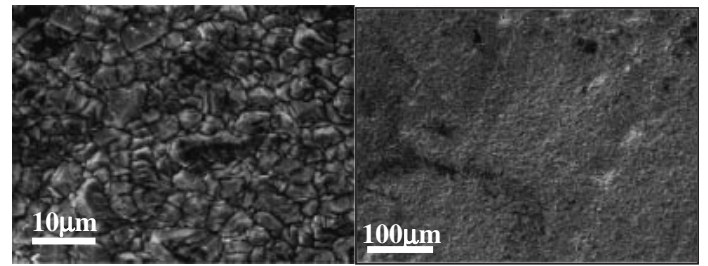

(d)

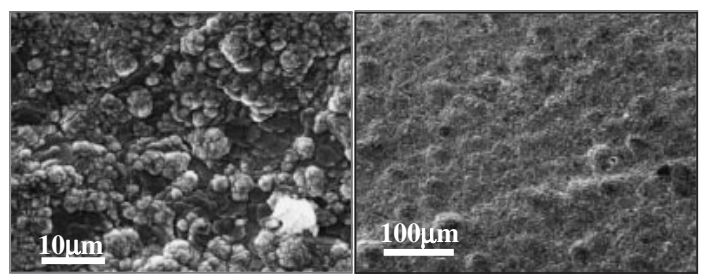

(e)

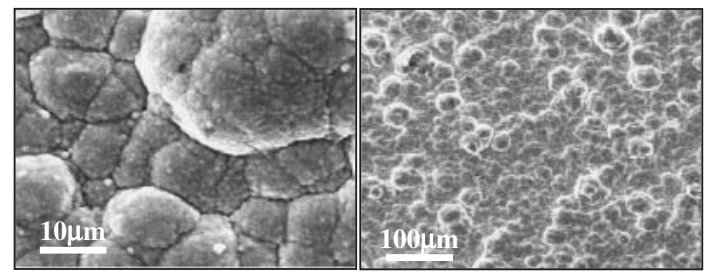

Fig. 7 Typical SEM images of the alloys electro-deposited at a current density of $700 \mathrm{Am}^{-2}$ for $1.8 \mathrm{ks}$ in (a) bath 5, (b) bath 10 , (c) bath 3 , (d) bath 9 and (e) bath 4 at $45^{\circ} \mathrm{C}$.

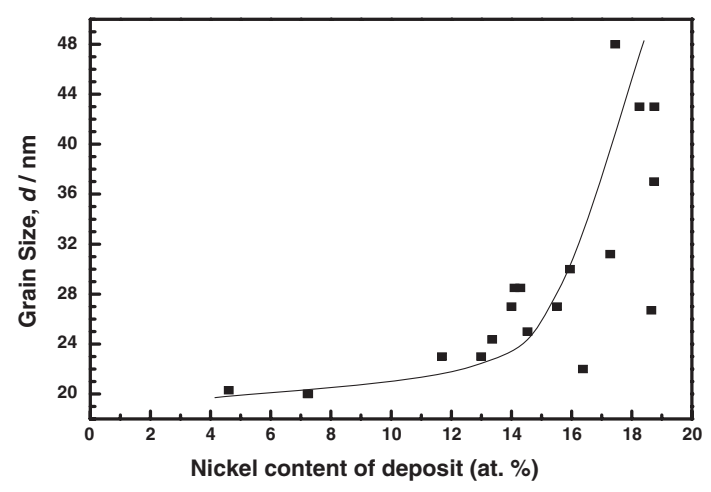

Fig. 8 Estimated grain sizes of the electrodeposits obtained by Scherrer's formula as a function of alloy composition. Alloys were deposited at $45^{\circ} \mathrm{C}$ and a current density of $700 \mathrm{Am}^{-2}$.

electrodeposit to the other. In general, (600) reflection increases with deposition time (Fig. 6(a-d)). When different solutions are compared, it is strongly revealed that the nickelrich baths favor (600) texture while the zinc-rich baths favor the (330) texture. This is true even for the electrodeposits with similar composition but obtained in different baths.

Typical SEM images of the deposits are shown in Fig. 7. Relatively smoother deposits accompanied by finer morphological features are formed in the nickel rich baths. The surface patterns primarily correspond to the protuberances resulting from the growth pattern of the deposits. It was not possible to resolve grain structure by SEM. Figure 7 clearly shows that the deposit quality strongly depends on the composition of plating bath, although it has less pronounced effects on the alloy composition.

The grain sizes were estimated from X-ray peak broadening with the help of Scherrer's formula as given below:

$$
\mathrm{d}=0.94 \lambda / \mathrm{B} \cdot \operatorname{Cos} \theta
$$

where

$d=$ grain size $(\mathrm{nm})$

$\lambda=$ wavelength of X-ray used (nm)

$\theta=$ diffraction angle (degrees)

$B=$ full width half maximum (FWHM) of X-ray diffraction peak (rad.)

As shown in Fig. 8, the grain size varies with the alloy composition although it remains in the nano-scale range. The grain size decreases with a decrease in nickel content of the deposit. In this way, the smaller grain size of about $24 \mathrm{~nm}$ has been obtained in $\gamma$-phase when it is highly deficient in nickel with respect to its stoichiometric requirement $(19.3 \% \mathrm{Ni})$. Hence, large concentration of point defects (substitutional and/or vacancies) seems attributable to a decrease in the grain size.

Hardness is also found to be a function of alloy composition as shown in Fig. 9. It is observed that with increasing amount of nickel in the deposit, the hardness increases sharply from $150 \mathrm{KHN}$ at $12 \% \mathrm{Ni}$ to $450 \mathrm{KHN}$ near stoichiometric composition of $\mathrm{Ni}_{5} \mathrm{Zn}_{21}$. Comparison of Figs. 8 and 9 indicates that the hardness increases with an increase in grain size. Hence, the behavior is opposite to HallPetch relationship, suggesting the grain boundary sliding as a primary mode of deformation for these nanocrystalline alloys. $^{26)}$

\section{Discussion}

\subsection{Nanocrystallinity of the deposit}

Alfantazi and Erb et al. ${ }^{12)}$ prepared nanocrystalline $\mathrm{Zn}-\mathrm{Ni}$ coatings in the same electrolyte by pulse plating. However, 


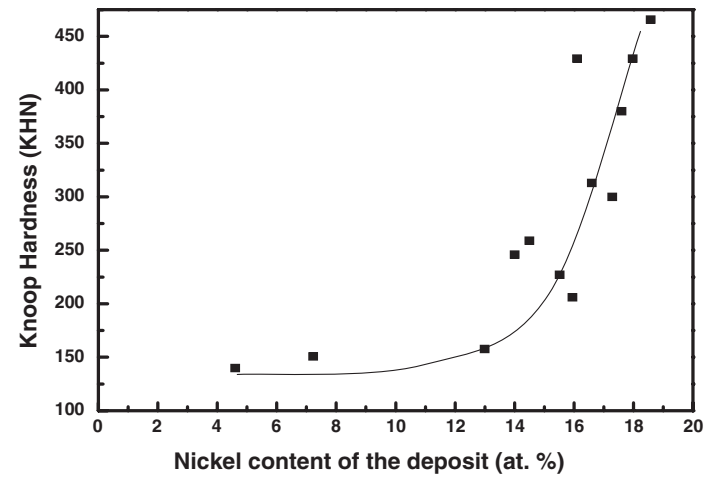

Fig. 9 Knoop hardness (obtained at a load of $0.2 \mathrm{~kg}$ ) of the electrodeposits as a function of alloy composition. Alloys were deposited at $45^{\circ} \mathrm{C}$ and a current density of $700 \mathrm{Am}^{-2}$.

we have been successful in obtaining nanocrystalline alloys with a grain size as low as $20 \mathrm{~nm}$, with simple DC plating at $700 \mathrm{Am}^{-2}$. The grain size has been found to be a strong function of the alloy composition. It reduces with a decrease in the nickel content and deviation from the stoichiometric composition of $\mathrm{Ni}_{5} \mathrm{Zn}_{21}$. It appears that the point defects, formed due to deviation from stoichiometric composition, are mostly accommodated at the grain boundaries resulting in an increased grain boundary area accompanied by a smaller grain size.

There are two modes of deformation of the nanocrystalline alloys that can be identified by the variation of hardness with grain size. ${ }^{26)}$ For coarse grained alloys, hardness increases with a decrease in grain size following a famous Hall-Petch relationship ${ }^{27,28)}$ as the deformation is based on dislocation glide. Below a critical grain size, however, grain boundary sliding is favored, instead of dislocation glide, resulting in an increase in hardness with an increase in grain size. ${ }^{26}$ ) $\mathrm{We}$ have found that both the hardness and the grain size increase with the nickel content of our alloys. We believe that increase in hardness is not primarily a function of composition as the point defects decrease with increase in nickel content towards stoichiometry. Accordingly, the increase in hardness is attributable to the increase in grain size owing to the grain boundary sliding as a primary mode of deformation. As the intermetallic compounds resist the dislocation movement because of large burger's vector ${ }^{29)}$ grain boundary sliding may be favored, allowing a relatively large critical grain size at which the primary deformation modes are switched. This seems to be a reason that grain boundary sliding has appeared as a primary mode of deformation at grain sizes of $20-50 \mathrm{~nm}$.

\subsection{Phases formed}

Several kinds of baths are used for electrodeposition of $\mathrm{Zn}$ $\mathrm{Ni}$ alloys. The chloride baths are preferred for improved micro-throwing power. ${ }^{4)}$ Our baths contained only chlorides of nickel and zinc along with boric acid. The commonly used additive, i.e., $\mathrm{NH}_{4} \mathrm{Cl}$, was not used. The deposition temperature was $45^{\circ} \mathrm{C}$. The XRD results reveal that only $\gamma$-phase forms in a wide range of composition of plating bath and the alloy composition varies from about 12 to $18 \%$ nickel. Only in case of zinc-rich bath 4 where the alloy contains $\sim 5-8 \%$ nickel, a mixture of $\gamma$ and $\eta$-phases is formed. Interestingly, $\delta$-phase $\left(\mathrm{Ni}_{3} \mathrm{Zn}_{22}\right)$ whose composition lies between $\eta$ and $\gamma$ - phases has not been observed in our electro-deposited alloys. A large number of authors have observed $\delta$-phase coexisting with either $\eta$ or $\gamma$-phase when the zinc content of the alloy exceeds the solubility limit of zinc in the $\gamma$-phase. ${ }^{30,31)}$ However, the baths used by them contained either sulfates, or chlorides with $\mathrm{NH}_{4} \mathrm{Cl}$ causing higher $\mathrm{pH}$ as compared to our chloride baths. Therefore, lower $\mathrm{pH}$ of chloride baths containing boric acid without $\mathrm{NH}_{4} \mathrm{Cl}$ seems useful for preparing single-phase alloys comprising $\gamma$-phase. It is worth-mentioning that single-phase alloys are believed to provide better corrosion resistance in comparison with twophase alloys.

\subsection{Anomalous Codeposition}

A clear anomalous codeposition has been observed in the simple chloride baths used in this work for alloy deposition. Even a minute cathodic current associated with the deposition of pure nickel has not been observed during cathodic scan before the codeposition of both the alloy constituents commenced (Fig. 2-4). The anomalous codeposition is attributed to the adsorbed layer of $\mathrm{Zn}(\mathrm{OH})_{2}$ at the surface that is reduced to metallic form to allow the deposition of zinc. $^{32)}$ In this way, the $\mathrm{Zn}(\mathrm{OH})_{2}$ acts as an intermediate product. ${ }^{33)}$ The alloy composition has been found to be affected by plating bath composition as far as the thickness is small and zinc content of the alloy is high. However, the nickel content of the alloy keeps increasing with thickness until it reaches about $18 \%$ and further increase seizes to occur suggesting a limiting composition that can be formed by DC plating in the chloride bath. The adsorbed $\mathrm{Zn}(\mathrm{OH})_{2}$ layer is expected to contain nickel cations that are also reduced along with zinc cations to form an alloy layer. ${ }^{33)}$ Higher concentration of nickel cations in the adsorbed hydroxide layer due to an increased concentration of nickel chloride (or a decrease in the concentration of zinc chloride) in the plating bath may lead to higher nickel content in the alloy layer. This seems to be a reason for obtaining higher nickel content in the alloy when deposition is carried out in a nickel-rich bath. This is particularly true for short time deposition. We have found an upper limit of nickel content in the alloy to be about $18 \%$. We consider that the adsorbed $\mathrm{Zn}(\mathrm{OH})_{2}$ layer does not allow its nickel content to exceed a certain limit. Hence its nickel content, apparently, saturates with deposition time (due to enrichment of nickel in the underlying alloy layer) or increased concentration of nickel in the solution. As a result, the nickel content of the alloy formed from nickel-saturated $\mathrm{Zn}(\mathrm{OH})_{2}$ remains at an upper limit of about $18 \%$.

\subsection{Effect of bath composition}

In spite of the fact that alloy composition does not change significantly with the composition of plating bath, particularly, when the nickel content reaches its maximum value of about $18 \%$, the morphology of the deposits and crystallographic orientation (texture) strongly depend on the composition of plating bath. The texture is also found to depend on deposition time. It appears that the adsorbed $\mathrm{Zn}(\mathrm{OH})_{2}$, which acts as a precursor for electrodeposits, changes its physical form (possibly the crystallographic arrangement of adsorbed ions) with deposition time and composition of plating bath, thus, altering the texture of the electro-deposited alloy. 


\subsection{Dissolution behavior}

The dissolution of the alloys has been studied by cyclic voltammetry and chronopotentiometry. The main anodic peaks in voltammograms and the anodic plateaus in chronopotentiograms correspond to the dissolution of $\eta-, \gamma$ and $\alpha$-phases in the order of increasing potential. The dissolution also involves dezincification. Furthermore, the formation of $\alpha$-phase in our solution at $45^{\circ} \mathrm{C}$ has only been possible by dezincification of $\gamma$-phase.

It may be noticed that the anodic peak $\mathrm{C}$ (Fig. 2) has been assigned to the dissolution of porous nickel by other authors. ${ }^{9)}$ The lower dissolution potential than electrodeposited nickel was believed to be due to porous nature. It has been experimentally confirmed in this work that this peak $\mathrm{C}$ (and plateau III) involves the dissolution and dezincification of $\alpha$ phase with high zinc content. Its low (more active) dissolution potential with respect to electrodeposited (pure) nickel is primarily attributable to its high zinc content.

\section{Summary}

(1) Zn-Ni alloys with a composition of $5-18 \% \mathrm{Ni}$ have been formed by DC plating in additive free chloride bath. The estimated grain size has been found to fall between $20-50 \mathrm{~nm}$. The constitutional point defects concentrating at grain boundaries seem responsible for increase in grain boundary area and, hence, a decrease in grain size.

(2) The micro hardness ranged between 150 to $450 \mathrm{KHN}$. It increased with grain size showing a break down of Hall Petch relationship at grain sizes below $50 \mathrm{~nm}$. This behavior has been attributed to grain boundary sliding as a predominant mode of deformation.

(3) The composition of thin deposits obtained during voltammetry and short time deposition depended on the composition of plating bath. The composition of thicker deposits showed less pronounced dependence on bath composition, particularly when nickel content reached a limit of about $18 \%$. Increased nickel content in the plating bath resulted in the formation of smoother deposits with relatively enhanced (600) reflections in XRD patterns, in comparison with zinc-rich baths.

(4) The results can be explained on the basis of formation of an adsorbed $\mathrm{Zn}(\mathrm{OH})_{2}$ layer responsible for codeposition. The composition of the electro-deposited alloy follows the changes in the composition of $\mathrm{Zn}(\mathrm{OH})_{2}$ layer, i.e. its nickel content, which in turn, is controlled by the composition of plating bath and the underlying alloy layer whose composition changes with deposition time. When the nickel content of $\mathrm{Zn}(\mathrm{OH})_{2}$ saturates at a certain level, the nickel content of the electro-deposited alloy also saturates to about $18 \%$, irrespective of the plating bath composition.

(5) Dissolution of the alloys involved pronounced dezincification. It has been revealed that $\alpha$-phase forms as a result of dezincification of $\gamma$-phase and that the last dissolution peak in voltammograms does not corre- spond to the dissolution of porous nickel as suggested by other authors. Instead, this peak corresponds to the dezincification and dissolution of $\alpha$-phase (with higher zinc content in solid solution).

\section{REFERENCES}

1) J. Ahmad, K. Asami, A. Takeuchi, D. V. Louzguine and A. Inoue: Mater. Trans. 44 (2003) 911-916.

2) M. Mehmood, N. Kawaguchi, H. Maekawa, Y. Sato, T. Yamamura, M. Kawai, K. Kikuchi and M. Furusaka: Mater. Trans. 44 (2003) 1659_ 1662.

3) M. Mehmood, N. Kawaguchi, H. Maekawa, Y. Sato, T. Yamamura, M. Kawai and K. Kikuchi: Mater. Trans. 44 (2003) 259-267.

4) D. E. Hall: Plat. Surf. Finish. 71 (1983) 59.

5) S. R. Rajagopalan: Met. Finish. 70 (1972) 52-56.

6) S. A. Watson: A Nickel Development Institute Review Series no. 13001, (1988).

7) A. Brenner: Electrodeposition of Alloys, Vol. I \& II, (Academic Press, New York and London, 1963).

8) H. Enomoto and T. Omi: Alloy Plating, (Nikkan Kogyo Shimbunsha, Tokyo, 1987) 112.

9) S. Swathirajan: J. Electrochem. Soc. 133 (1986) 671-680.

10) A. Petrauskas, L. Grincevičienè, A. Česūniene and E. Matulionis: Surf. Coat. Technol. 192 (2005) 299-304.

11) A. Petrauskas, L. Grincevičienè, A. Česūniene and R. Juškènas: Electrochim. Acta 51 (2006) 4204-4209.

12) A. M. Alfantazi, J. Page and U. Erb: J. App. Electrochem. 26 (1996) 1225-1234.

13) A. M Alfantazi, A. M. El-Sherik and U. Erb: Scripta Metall. Mater. 30 (1994) 1245-1250.

14) K. Asami, B.-P. Zhang, M. Mehmood, H. Habazaki and K. Hashimoto: Scripta Mater. 44 (2001) 1655-1658.

15) M. Mehmood, E. Akiyama, H. Habazaki, A. Kawashima, K. Asami and K. Hashimoto: Corros. Sci. 42 (2000) 361-382.

16) M. Mehmood, E. Akiyama, H. Habazaki, A. Kawashima, K. Asami and K. Hashimoto: Corros. Sci. 41 (1999) 1871-1890.

17) K. Hashimoto, M. Mehmood, E Akiyama, H. Habazaki, A. Kawashima and K. Asami: Corros. Sci. 41 (1998) 477-499.

18) M. Mehmood, E. Akiyama, H. Habazaki, A. Kawashima, K. Asami and K. Hashimoto: Mater. Sci. Forum 289-2 (1998) 629-639.

19) M. Mehmood, B.-P. Zhang, E. Akiyama, H. Habazaki, A. Kawashima, K. Asami and K. Hashimoto: Corros. Sci. 40 (1998) 1-17.

20) J. Ahmad, K. Asami, A. Takeuchi, D. V. Louzguine and A. Inoue: Mater. Trans. 44 (2003) 1942-1947.

21) J. Ahmad, K. Asami, A. Takeuchi and A. Inoue: Mater. Trans. 44 (2003) 705-708.

22) B. D. Cullity: Elements of X-Ray Diffraction, (Addison-Wesley, 1978).

23) Allen J. Bard: Electrochemical Methods, (John Wiley \& Sons, 1980).

24) M. G. Fontana: Corrosion Engineering, International Edition, (MacGraw-Hill, Singapore, 1987).

25) David R. Gaskell: Introduction to Thermodynamics of Materials, (Taylor \& Francis, New York and London 2003).

26) T. Yamasaki, P. Schlomacher, K. Ehrlich and Y. Ogino: Nanostruct. Mater. 10 (1998) 375-388.

27) E. O Hall: Proc. Phys. Soc., B 64 (1951) pp. 747-753.

28) N. J. Petch: J. Iron and Steel Institute 174 (1953) 25-28.

29) G. E. Dieter and D. Bacon: Mechanical Metallurgy, SI Metric Edition, (McGraw-Hill, UK, 1988).

30) M. M. Abou-Krisha: Appl. Surf. Sc. 252 (2005) 1035-1048.

31) J. B. Bajat, M. D. Maksimović, V.B. Mišković-Stanković and S. Zec: J. App. Electrochem. 31 (2001) 355.

32) K. Higashi, H. Fukushima, T. Urakawa, T. Adaniya and K. Matsudo: J. Electrochem. Soc. 128 (1981) 2081-2089.

33) C. E. Lehmberg, D. B. Lewis and G. W Marshall: Surf. \& Coat. Technol. 192 (2005) 269-277. 